\title{
Pheochromocytoma and Paraganglioma Pathologic Regional Lymph Nodes TNM
} Finding v8

National Cancer Institute

\section{Source}

National Cancer Institute. Pheochromocytoma and Paraganglioma Pathologic Regional Lymph Nodes TNM Finding v8. NCI Thesaurus. Code C141124.

A pathologic finding about one or more characteristics of pheochromocytoma and paragang lioma, following the rules of the TNM AJCC v8 classification system as they pertain to staging of regional lymph nodes. 